\title{
Naturation of Mexico City: cost benefit analysis of an air quality improvement proposal
}

\author{
E. Villaseñor ${ }^{1}$, E. Ortiz ${ }^{1}$, G. Navas ${ }^{2} \&$ E. Alemón ${ }^{3}$ \\ ${ }^{I}$ Instituto Mexicano del Petróleo, Mexico \\ ${ }^{2}$ Universidad Autónoma de Chapingo, Mexico \\ ${ }^{3}$ Instituto Nacional de Investigaciones Nucleares, Mexico
}

\section{Abstract}

The naturation project consist in adapting plants (crasulaceae) to roofs and other concrete surfaces in order to reduce, among others, particulate matter levels in air. Particulate matter of less than 10 microns can cause severe respiratory disease and minor symptoms. In this work we assess the impact of particles in public health, relating that impact to costs of hospitalization and reduction of productivity in the Mexico City Metropolitan Area (MCMA), based on works for another countries, while better data are obtained. On the other hand, an estimation of the effect in reducing particles by the naturation project is made in order to assess the savings in costs due to public health damage, regarding them as benefits. The particle's mean level concentrations would decrease 15 percent. A cost analysis is performed in order to estimate a cost/benefit ratio through different periods of time, using three different scenarios. With US \$ 621 million of benefits per year, we obtained the recovery of the investment, measured in social terms, in a 25 -year period. The time of recovery could be reduced if cheaper, but high quality material could be developed for the project. Additional risk analysis showed that a 30 year period is a good horizon when random cash flows between optimistic and pessimistic scenarios are considered.

When compared to reforesting, this project results very expensive to carry out. Reforesting, for the case of optimal planning, is recommended, as naturation can be a complementary program for a far future. 


\section{Introduction}

While world population has increased five-fold in the past 200 years, the number of people living in urban areas has increased five times more. Within the next decade, half of the world's population will be living in cities, and along the twenty-first century a more uniform level of urbanization will spread around the world, tending toward the $75 \%$ levels of urbanization prevalent in industrialized countries. This implies a virtual reversal of the current ratio of urban to rural population in developing countries, where $70 \%$ of people still live in rural areas, Carley [1]. This growth have always tended to worsen the ecology, so cities world-wide are facing with the task of improving their urban bioclimatic situation. One of these tasks might be the Naturation.

The process of naturation consists in the treatment of roofs, facades and other high reflecting surfaces, e.g. parking zones, with water proof layers so specific plants can be seeded and allowed to grow without damaging buildings. The effects of this system are oxygen production, $\mathrm{CO}_{2}$ reduction, suspended particles retention, water storing and improvement of the microclimate. In addition, the naturated building is heat isolated and reduces the noise. Ortiz [2].

The main goals for improved air quality in extensive naturation of building surfaces (biotope planting) are:

- The roughness of building surfaces is increased so the dust load (particles emission) and traffic noise are reduced.

- Optimize the atmospheric humidity

- Diminish ozone levels in the air by reducing albedo surfaces

The main pollutants removed from air by plants are particles. The main source for particle emission in the MCMA is from biogenic rather than antropogenic IMADA [3]. This is a direct effect of deforested aikaline land, which was the bottom of Texcoco Lake many years ago and deforested and eroded mountain ranges surrounding the city.

In this work three cases were studied to assess the value of particles retention by the project:

- A simple deposition/retention model is used Woodruff [4]. This model incorporates into mathematical formulation descriptions of soil rugosity, type of vegetation, origin of specific emissions.

- The main findings reported on selected researches, Margulis [5], Pardón [6], Dürr [7] and

- A database set of values RAMA [8] to compare the effect of modifying particle emissions and concentrations where a city greening project is to be implemented.

It is important to carry out the cost/benefit analysis before implementation of the naturation, so scenarios were very helpful to predict the change in particle concentration and the effects that this could have on public health.

The effect on public health and the associated costs were estimated using dose-response functions reported in studies in this matter. Those studies were 
carried out in Chile Ostro [9], Indonesia Ostro [10] and Mexico city Margulis [5]. Then estimated public health impacts and costs of the program were evaluated using a cost/benefit ratio. The monetization of benefits included the mean value of a life, average wages and medical costs when available, for example, Chronic Bronchitis. Avila [11]

Due to the uncertainty of our assessment, a risk analysis was performed using triangular distributions for optimistic, most likely and pessimistic cash flows for each period. The simulation algorithm takes the planning horizon to 30 years.

\section{Objectives}

To assess benefits due to modification in $\mathrm{PM}_{10}$ concentrations related to changes in emissions associated with the implementation of a naturation project in MCMA.

To determine the cost-benefit ratio in the evaluation of naturation reliability.

\section{Methodology}

The region considered to naturate is the metropolitan area of Mexico city, this includes the neighborhoods, which belong to State of Mexico and together make a 20 million inhabitants metropolis, spreading in $1498 \mathrm{~km}^{2}$.

\subsection{Costs of naturation}

The associated costs with the naturation have been considered, these include roofs treatment with waterproof elements, the adapted plants needed to seed those surfaces and costs related to support the system weight, in necessary cases. The people who have the responsibility to develop the technical part (Construction) provided the costs, and they were about $27.50 \mathrm{US}$ Dollars $/ \mathrm{m}^{2}$ so, multiplied by the total area to naturate total cost was obtained. The urban area of MCMA is about $1498 \mathrm{~km}^{2}$. This area was estimated using data from Geographical Information Systems, which incorporated satellite images. Ortiz [2]. As it was proposed to naturate a $20 \%$ of the urban surface, the total area is $299600000 \mathrm{~m}^{2}$.

\subsubsection{Effects on health costs}

Decrease in pollutants concentrations means decrease in morbidity and mortality. To estimate the benefits, dose-response functions, which correlate particle concentrations with mortality and morbidity, were used. A dose-response function is a sigmoidal curve which in a given range of concentrations can be expressed linearly, it is a mathematical correlation between the independent variable $\left(\mathrm{PM}_{10}\right.$ concentrations in the air) and the dependent variable (cases of deaths, chronic illness, restricted activity days, etc.). The main sources of information of this kind for this work were obtained from the studies realized in 
Jakarta, Santiago de Chile and Mexico city (Ostro[9], [10] and Margulis[5]), three of the most suffering by particles cities in the world. The value to realize the calculations was the average $\mathrm{PM}_{10}$ in the labor hours, when population is exposed to them, and is equal to $180 \mu \mathrm{g} / \mathrm{m}^{3}$

To monetize the mortality and morbidity, different techniques had to be used. The most used criterion to assess benefits due to mortality reduction, is to multiply the total decrease in cases by the statistical value of a life. The morbidity involves expenses in hospitals, medical care, improductivity and shadow prices such the amount that a given person is willing to pay to reduce the pain. Average wage was used to assess the benefit obtained when lost labor days decrease. All Hospital admissions, emergency room visits and other morbidity cases were treated as Restricted Activity Days (RAD), the only exception was for chronic bronchitis, for which an study was realized in 1993 [11], which monetizes the cost of each case per year.

For risk analysis optimistic scenario corresponds to minimum cost and maximum particle retention and the pessimistic scenario is exactly the inverse. There is a most likely scenario, generated using the central estimates for retention and cost of build. Using a Montecarlo process with triangular statistical distribution for the cash flows at each period of time, the probability to gain or loss in a 30 year planning horizon was assessed.

\subsection{Assessing numbers for cases}

Case A.- The theory of deposition of particulate matter due to convective transport and diffusion from surfaces was used to describe $\mathrm{PM}_{10}$ behavior. Values have been generated to different types of terrain which consider the particles retention in different kinds of surfaces. Those values are then interpolated in graphics, which resume the results of many experimental data in two axes, correlating soil rugosity factors with retention rate. Woodruff[3], 1964. See figure 1. Naturation is well represented as herbaceous surface, so the value of four inches was considered for interpolation.

In figure 1 , for a factor number of 4 inches, a $50 \%$ of retention is obtained for particles. In this work, we consider that $20 \%$ of the urban surface was naturated following a special geometric scheme. This implies that total particle removal for the metropolitan surface will be $10 \%$, which is the lowest estimate for particle retention. 


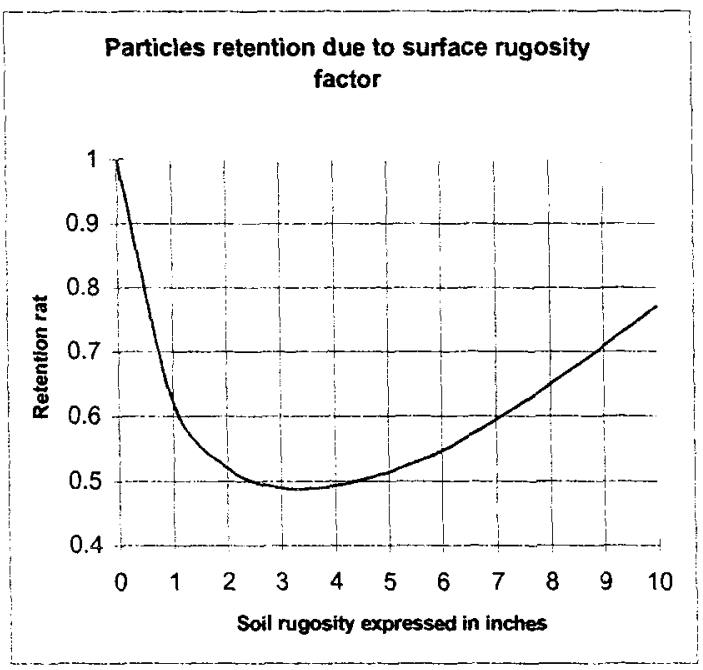

Figure 1: Interpolation graphic.

Case B.- In order to establish a comparison with other measures, in Europe a retention value of $0.2 \mathrm{Kg}$ of particles $\mathrm{PM}_{10}$ per $\mathrm{m}^{2}$ per year has been obtained Dürr[8]. That means $14 \%$ of total emissions annually according to emissions inventory of 1994 [12]. So this is the most likely estimate for the retention rate due to naturation.

Case C.- A third value was obtained when values of selected stations of the automatic atmospheric monitoring net were compared in dry and rain seasons See Figure 5. In rainy season, the neighborhoods of those stations are covered with native herbaceous plants which randomly spread through the terrain. These plants make a good example of simulating how naturations will work. The measures obtained show a $20 \%$ less particles concentrations in summer, RAMA [9], so that is the optimistic estimate for particle retention.

In order to assess impacts through a risk analysis, the estimations aforementioned were set to 10,15 and $20 \%$ respectively, so a triangular distribution could be used to perform risk analysis.

Table 1. - Few types of soil use and its associated rugosity factor

\begin{tabular}{|l|c|}
\hline SOIL TYPE & RUGOSITY FACTOR (INCHES) \\
\hline $\begin{array}{l}\text { Crops and grass } \\
\text { flowers }\end{array}$ & 4 \\
\hline Herbaceous surface & 18 \\
\hline Arbustive surface & 4 \\
\hline
\end{tabular}




\subsection{Costs and benefits.}

The cost was given by $\mathrm{m}^{2}$ according to evaluations from the people who will implement the technical part of the project. A US $\$ 27.50$ is the cost. Multiplying it by the total surface to naturate, it gives a total cost of 8.24 billion dollars. The cheaper price considered for risk analysis was US \$20 per square meter and the more expensive was $\$ 35$.

Benefits were calculated assuming a $15 \%$ decrease in $\mathrm{PM}_{10}$ levels in atmosphere and then using the dose-response functions to estimate decrease in cases of mortality, morbidity and minor symptoms. See Table 2

Table 2.- Benefits obtained.

\begin{tabular}{|l|l|l|l|}
\hline Cause & Cases (decrease) & Cost by case & Net benefit (mill.) \\
\hline Mortality & 456 & US \$ 75000 & US \$ 34.20 \\
\hline Morbidity & $8575430^{*}$ & US \$ 3.765/hr & US \$ 258.30 \\
\hline Chronic bronchitis & 33048 & US \$ 6110 & US \$ 201.92 \\
\hline Shadow benefits & ---- & $-\cdots--$ & US \$ 129.15 \\
\hline & & Total benefits & US \$ 623.57 \\
\hline
\end{tabular}

\subsection{Dose-response functions}

To obtain cases of mortality [5], morbidity [9, 10] (Restricted Activity Days, RAD) and other symptoms (Chronic Bronchitis [11]) associated with $\mathbf{P M}_{10}$ levels in air; dose response functions reported in literature were used.

$\Delta$ mortality (number of cases) $=0.5 * 1.69 /$ million $* \Delta \mathrm{PM}_{10}$

$\Delta \mathrm{RAD}=0.0575 * \Delta \mathrm{PM}_{10} /$ person*year

$\Delta \mathrm{CB}=6.12 * 10^{-5} * \Delta \mathrm{PM}_{10} /$ person $*$ year

When $20 \%$ and $10 \%$ retention rates are taken, the total benefits are US $\$ 831.43$ and US $\$ 415.71$ million respectively. To perform the Net Present Value analysis, which gave the net cash flows for every period in a time planning horizon, the next constants were taken

Price of the project increment rate (annually): 0.0519

Health and personal care goods inflation rate: 0.0541

Discount rate: $8.00 \%$ 


$$
\begin{aligned}
& P V_{C}=\sum_{i=1}^{n} \frac{C_{i}}{(1+r)^{i}} \\
& P V_{B}=\sum_{i=1}^{n} \frac{B_{i}}{(1+r)^{i}}
\end{aligned}
$$

Where PV is the present value of cost or benefit, $\mathrm{Ci}$ are the costs for each year, $\mathrm{Bi}$ the benefits for each year and $\mathrm{r}$ is an interest rate.

\section{Results}

Taking the central estimates for cost and benefits, and equations 4 and 5 , the period for investment recovery is 25 years Figure 2. In order to carry out risk analysis three scenarios were developed, optimistic scenario corresponds to minimum cost and maximum particle retention and the pessimistic scenario is exactly the inverse. There is a most likely scenario, generated using the central estimates for retention and cost of construction. For a 30 year period analysis, the probability to gain, that is cost is lower than benefits, is about $86 \%$. The analysis was performed using a Montecarlo simulation process with triangular distribution. When compared to reforestation, which has only US $\$ 35$ million costs annually and can retain $66 \%$ of the emitted particles is more convenient to reforest rather than naturate. EGCA [13]

\section{Discussion}

Benefits are limited only to public health related with respiratory diseases or symptoms. However, savings in energy consumption, mental health due to noise reduction, water disposal and treatment and another intangible costs have not been estimated.

Although the reforestation would be better in terms of money, some greening of the urban surface could be very healthy to the urban environment. In this sense, more studies should be done to determine whether the naturation or an urban re-ordering project to increase green surfaces must be implemented in a long time horizon. 
Figure 2: $\mathrm{E}$ is the recovery of investment period, where costs (squares line) are equal to benefits. The triangles line shows the cumulative cash flow at net present value

\section{Conclusion}

Naturation modifies atmospheric concentrations of $\mathrm{PM}_{10}$, this modification is estimated to decrease $15 \%$ the actual levels of that pollutant, with a variation of $33.3 \%$. This will diminish mortality and morbidity cases along the city, as well as labors absenteeism due to Restricted Activity Days. With a cost of 27.50 dollars per $\mathrm{m}^{2}$ and particle retention of $15 \%$, the minimum planning term is 25 years. The success of the project depends of costs of construction. The cheaper of cost is the lower cost/benefit ratio. Risk analysis supports a 30 -year period planning if probability to have profits has to be higher than $80 \%$. This project could be a complement of reforestation, increasing the green surface of the city without demolitions or urban reordering, which represent a multi billionaire cost actually.

\section{Acknowledgments}

Thanks to the Instituto Mexicano del Petróleo to support this work, made in the fellowship program for Oil Industry human resources training.

\section{References}

[1] M. Carley and I Christie, Managing Sustainable Development, University of Minnesota Press, Minneapolis, p. 27, 1993. 
[2] G. Navas, E. Ortiz, Modelación del Efecto en la Calidad del Aire Debido a la Naturación en la Zona Metropolitana del Valle de México. Informe Técnico Parcial, GCA98002, Instituto Mexicano del Petróleo. México, 1998.

[3] Edgerton,S., Ortiz,E, ProyectolMADA.

Http://wolf.eco.imp.mx/imada/general.html

[4] Woodruff N. P. and Siddoway F. H, A wind erosion equation. Soil Science Society proceedings, 1965. P. 602

[5] Margulis, S. Back-of-the-envelope estimates of environmental damage costs in Mexico. World Bank. WPS 824, Washington, January, 1992

[6] Pardón, M, Martínez, A.P., Health Impact of Air Pollution in Mexico. Submitted for publication

[7] Dürr. A, Dachbegruenung, Bauverlag, 160 S. Düselldorf, 1995

[8] RAMA Red Automática de Monitoreo Atmosférico. Database of hourly values for main pollutants in 32 stations distributed along Mexico city widespread. Mexico, 1986-1999

[9] Ostro, Bart, Air pollution and Mortality: Results from Santiago de Chile. World Bank Working Papers. WPS 1453, Washington, 1995

[10] Ostro, Bart. Estimating the Health Efects of Air Pollutants. A method with an application to Jakarta. World Bank Working Papers. WPS 1301, Washington, 1994

[11] Avila Burgos, L. et al. El costo social de la bronquitis crónica en la Ciudad de México. Una experiencia piloto. Rev. Salud pública Mex.; (38) 128-138, 1996

[12] Programa para Mejorar la Calidad del Aire en el Valle de México, 19952000. Gobierno del Distrito Federal. p. 75, Mexico, 1995.

[13] Informe Final, LA-12699, IMP/LANL, Estudio Global de la Calidad del Aire de la Zona Metropolitana de la Ciudad de México, Instituto Mexicano del Petróleo \& The Los Alamos National Laboratory, 1994 